\title{
The physical and optical properties of AZO thin films on teflon substrate at low deposition temperature by spray pyrolysis
}

\author{
Sofea Nabila Hazmin ${ }^{1}$, F.S.S Zahid ${ }^{2}$, N.S.M. Sauki ${ }^{3}$, M.H. Mamat ${ }^{4}$, M.N. Amalina ${ }^{5}$ \\ ${ }^{1,4}$ Nano-ElecTronic Centre (NET), Universiti Teknologi MARA (UiTM), Malaysia \\ 1,2,3,4,5 Faculty of Electrical Engineering, Universiti Teknologi MARA (UiTM), Malaysia
}

\begin{tabular}{l} 
Article Info \\
\hline Article history: \\
Received Oct 29,2019 \\
Revised Dec 31,2019 \\
Accepted Jun 14, 2020 \\
\hline Keywords: \\
Aluminium zinc oxide (AZO) \\
AZO thin film \\
Low deposition temperature \\
Spray pyrolysis \\
Teflon substrate
\end{tabular}

Teflon substrate

\begin{abstract}
This paper presents the physical and optical properties of AZO thin films on Teflon substrate at low deposition temperature by spray pyrolysis. In this study, the effect of different process parameters such as spray time and substrate to nozzle distance on the physical and optical characteristic of aluminium doped zinc oxide (AZO) deposited on Teflon substrates was investigated. The AZO thin films were successfully deposited onto Teflon substrate by spray pyrolysis technique at low deposition temperature. The physical analysis by X-ray diffraction (XRD) shows that the deposited Teflon substrate films have a preferred orientation along the direction (100) and (101). Optical measurements were conducted using Jasco/V-670 Ex Uv-Vis-NIR Spectrophotometer model to confirms that in visible ray it is possible to get good reflectance of AZO films with a reflection of $80 \%$. The values of band gaps Eg were calculated from the spectra of UV-Visible reflectance that were vary between 3.06 and $3.14 \mathrm{eV}$.
\end{abstract}

Copyright $(2020$ Institute of Advanced Engineering and Science. All rights reserved.

\section{Corresponding Author:}

Nur Amalina Muhamad,

Faculty of Electrical Engineering,

Universiti Teknologi MARA (UiTM) Cawangan Johor,

81750 Masai, Johor, Malaysia.

amalina0942@uitm.edu.my

\section{INTRODUCTION}

In resent time, Zinc oxide $(\mathrm{ZnO})$ semiconductor-based devices have attracted remarkable interest in science and technology field due to exciting and modern applications such as light sensor, gas sensor, piezo-electric devices and thermoelectric devices [1-7]. $\mathrm{ZnO}$ is an n-type direct band gap semiconductor materials that has a wide direct band gap oxide $(3.37 \mathrm{eV})$ and has large exciton binding energy $(60 \mathrm{meV})$ at room temperature [8-13]. High structural quality and low deposition temperature play important roles in the production of these various applications.

Therefore, several techniques have been developed including magnetron sputtering, ion plating and pulsed-laser deposition $[14,15]$. However, these techniques are complicated and expensive. Thus, low cost and simple alternative technique have been investigated to cope the problems [16]. Spray pyrolysis method is a simple and environmentally friendly method that can produce high quality crystalline AZO films without requiring high heat treatment process [17]. In addition, for manufacture of large scale optoelectronic devices, flexible substrate such as Teflon substrate is an ideal substrate material because it is commercially available and economical $[18,19]$.

This paper presents the physical and optical properties of AZO thin films on Teflon substrate at low deposition temperature by spray pyrolysis technique, which start from aluminium zinc oxide solution until the deposition of the solution onto heated Teflon substrate. In this work, our aim was to study AZO thin films deposited onto Teflon substrate at low deposition temperature. The effect of spray time and substrate to 
nozzle distance on physical and optical properties of AZO was studied. This research will bring significant contribution to nanoelectronic devices in the future.

\section{RESEARCH METHOD}

Aluminium Zinc Oxide (AZO) thin films were deposited onto Teflon substrates by spray pyrolysis method. The fabrication process involved were preparation of AZO solution, preparation of Teflon substrates and deposition of AZO thin films on Teflon substrates. AZO solution were synthesized using $8.78 \mathrm{~g}$ Zinc Acetate Dehydrate (ZAD) [Zn (CH3OO).2H2O] as precursor, 0.1516g Aluminium Nitrate Nanahydrate $\mathrm{Al}(\mathrm{NO} 3) 3.9 \mathrm{H} 2 \mathrm{O}$ as dopant, $2.4 \mathrm{ml}$ Monoethanolamine (MEA) $(\mathrm{HOCH} 2 \mathrm{CH} 2) \mathrm{NH} 2$ as stabilizer and 2-methoxyethanol as solvent. The solution contains MEA+AL+MEA were mix with 2-methoxyethanol until it reached $100 \mathrm{ml}$ of solution. The solution was magnetically stirred with $80^{\circ} \mathrm{C}$ heat for 3 hours and then left overnight for aging.

Before AZO thin film deposition, the substrates were cleaned to remove any contaminants present on the surface of Teflon substrates. Teflon substrates were firstly cut into $2 \mathrm{~cm} \times 2 \mathrm{~cm}$ and cleansed in acetone solution, dioxide (DI) water, methanol solution and DI water in ultrasonic bath for 20 minutes. Then, the substrates were dried using nitrogen (N2) gas for drying process.

The deposition of AZO was carried out using spray pyrolysis method. The carrier gas used was argon gas which was kept with 1.0 bar carrier gas pressure during all the experiment. The air produced by the compressor was connected to the atomizer which was positioned at 3 different distance above the substrate that was preheated at a temperature of $180^{\circ} \mathrm{C}$ for 30 minutes. The spray time also will be varied to 6 different time. The whole experiment was carried out in an enclosed chamber. The parameters for deposition of AZO thin films will be listed in Table 1. Finally, the deposited thin films were dried in furnace with temperature $180^{\circ} \mathrm{C}$ for 30 minutes.

Table 1. Process Parameters for Deposition of AZO thin Films

\begin{tabular}{cc}
\hline Parameter & Value \\
\hline Spray nozzle diameter & $0.2 \mathrm{~mm}$ \\
Substrate temperature & $180^{\circ} \mathrm{C}$ \\
Spray time & 20 \\
Carrier gas pressure & $10 \mathrm{~s}, 20 \mathrm{~s}, 30 \mathrm{~s}, 40 \mathrm{~s}, 50 \mathrm{~s}$ and $60 \mathrm{~s}$ \\
Substrate to nozzle distance & $35 \mathrm{~cm}, 40 \mathrm{~cm}$ and $45 \mathrm{~cm}$ \\
\hline
\end{tabular}

The physical measurement of AZO thin films was characterized by X-ray diffractometer (XRD) for the surface morphology and the crystallinity properties. The optical properties were measured using Jasco/V-670 Ex Uv-Vis-NIR Spectrophotometer model at room temperature.

\section{RESULTS AND ANALYSIS}

\subsection{Physical Characterization}

The crystallographic properties of the spray deposited AZO thin film on the Teflon substrate at a low substrate temperature of $180^{\circ} \mathrm{C}$, were investigated by X-ray diffraction (XRD). For all samples, (100) and (101) peaks are much higher than all other AZO thin films peaks. This is result from aluminium replacement in hexagonal lattice [20]. The observed diffraction peaks at (100) and (101) planes are in good agreement with JCPDS card No. 36-1451 [21, 22]. The XRD pattern of as-prepared AZO thin film on Teflon substrate revealed that they were hexagonal wurtzite-type crystal structure. (100) and (101) diffraction peak is the only peak acquired from XRD films, indicating that there are no phase corresponding to other oxides.

The diffraction peak (100) and (101) was observed in the range of $31^{\circ}$ to $32.2^{\circ}$ and $37.2^{\circ}$ to $37.6^{\circ}$ respectively. Among 18 samples from $1 \mathrm{X}, 1 \mathrm{Y}$ and $1 \mathrm{Z}$ to $6 \mathrm{X}, 6 \mathrm{Y}$ and $6 \mathrm{Z}$, sample $3 \mathrm{X}, 4 \mathrm{Y}$ and $1 \mathrm{Z}$ have the smallest full widths at half-maximum (FWHM) of the diffraction peaks at (100) for three different value of substrate to nozzle distance. Figure 1 shows the XRD pattern for smallest values of (FWHM) for 3X, $4 \mathrm{Y}$ and $1 \mathrm{Z}$ thin films deposited on Teflon substrate by spray pyrolysis method. 


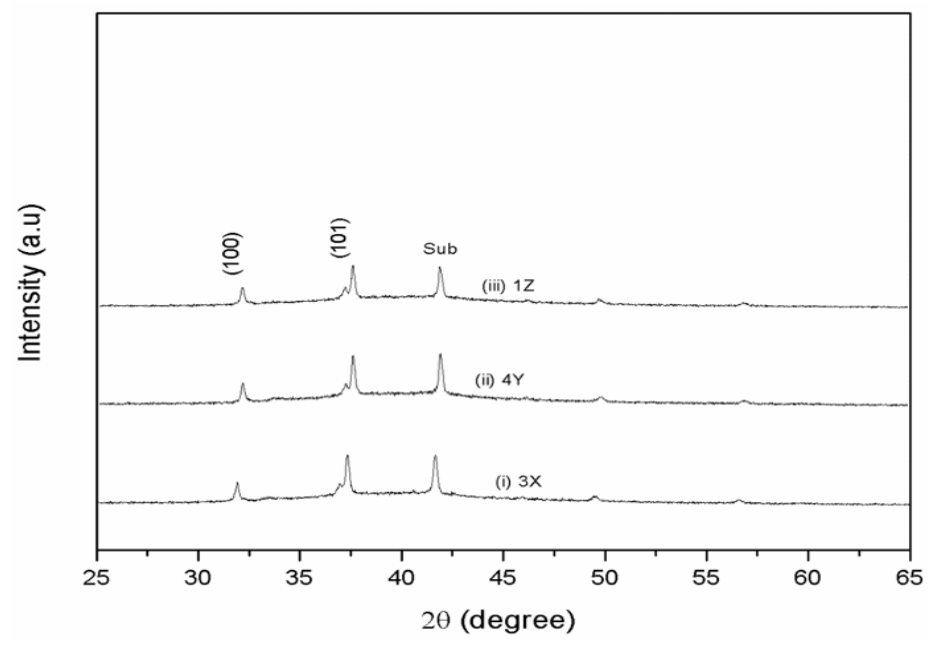

Figure 1. X-ray diffraction (XRD) pattern of (i) 3X, (ii) $4 \mathrm{Y}$ and (iii) $1 \mathrm{Z}$ thin films deposited on Teflon Substrate by spray pyrolysis method

According to previous researcher, for $\mathrm{ZnO}$ based materials, the peak broadening of nanocrystalline is correlated to crystallite size [23]. For instance, the FWHMs of (100) peaks for samples 3X, 4Y and 1Z were $0.17^{\circ}, 0.16^{\circ}$ and $0.17^{\circ}$ respectively. While FWHMs of diffraction peak (101) for same samples were $0.5^{\circ}, 0.6^{0}$ and $0.5^{\circ}$. The crystallite size of crystalline materials can be calculated from the FWHMs and $2 \theta$ of the diffraction peaks using the Scherrer's formula [24, 25].

$$
D=\frac{0.9 \lambda}{\beta \cos \theta}
$$

where $\mathrm{D}$ is the crystallite size, $\lambda$ is the wavelength of the incident $\mathrm{X}$-ray $(0.15406 \mathrm{~nm}), \beta$ and $\theta$ are the halfwidth at half maximum intensity (FWHM) of the diffraction peak and the Bragg angle at which the maximum peak intensity occurs. The calculated crystallite size (D) for each deposited AZO thin film were tabulated in Table 2. The crystallite size for diffraction peak (100) calculated using Scherrer equation shows increasing in value from distance $35 \mathrm{~cm}$ to $40 \mathrm{~cm}$ and then decreases in value from $40 \mathrm{~cm}$ to $45 \mathrm{~cm}$ of substrate to nozzle distance. This may cause by increasing spray time which also will increase the thickness of thin film. As stated by earlier researchers [26, 27], crystallinity increases due to increase in deposition time (spray time) which also imply to the thickness of thin films. Thus, from the XRD analysis it can be concluded that the best film prepared is sample $4 \mathrm{Y}$ which has the largest crystallite size $(46.30 \mathrm{~nm})$ with 40 seconds spray time and $40 \mathrm{~cm}$ substrate to nozzle distance.

Table 2. Structural Parameters of AZO thin Films

\begin{tabular}{cccc}
\hline Sample ID & Position of $(100)$ peak & FWHM $\left({ }^{0}\right)$ & Crystallite size $(D) \mathrm{nm}$ \\
\hline $3 \mathrm{X}$ & 31.91 & 0.17 & 44.40 \\
4Y & 32.14 & 0.16 & 46.30 \\
$1 \mathrm{Z}$ & 32.12 & 0.17 & 44.04 \\
\hline
\end{tabular}

\subsection{Optical Characterization}

Reflectance spectra of all samples are shown in Figures 2, 3 and 4, note that the reflectance spectra of all AZO thin films sample increase smoothly in the Ultraviolet (UV) region. AZO samples show nearly $80 \%$ reflectance except samples deposited at $45 \mathrm{~cm}$ substrate to nozzle distance in Figure 4 . The reflectance spectra in Figure 4 show non-uniform reflectance edge than samples prepared at $35 \mathrm{~cm}$ and $40 \mathrm{~cm}$ substrate to nozzle. Peaks of all samples in the visible region were observed to indication of maximum reflectance value for each individual AZO thin films [28]. 


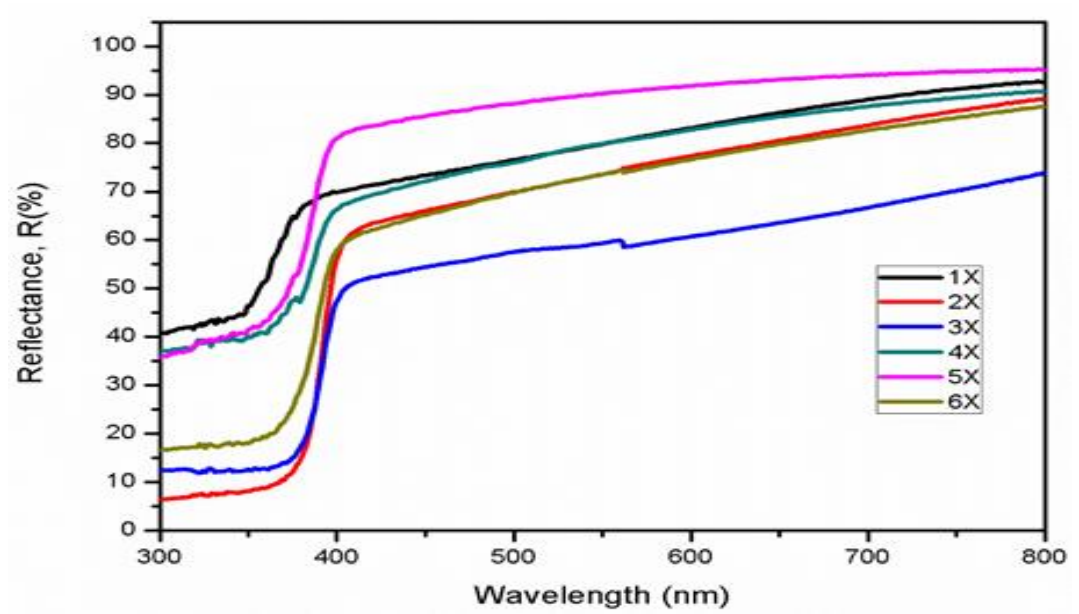

Figure 2. Optical reflectance spectra of AZO thin films prepared at $35 \mathrm{~cm}$ substrate to nozzle distance and six different spray time which are $10 \mathrm{~s}, 20 \mathrm{~s}, 30 \mathrm{~s}, 40 \mathrm{~s}, 50 \mathrm{~s}$ and $60 \mathrm{~s}$

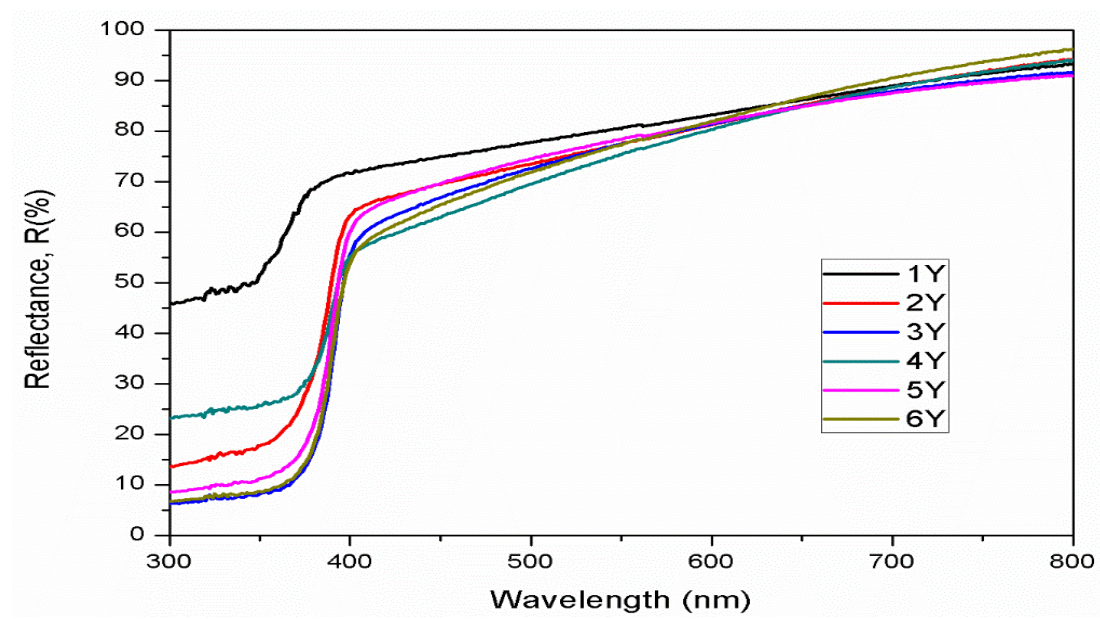

Figure 3. Optical reflectance spectra of AZO thin films prepared at $40 \mathrm{~cm}$ substrate to nozzle distance and six different spray time which are $10 \mathrm{~s}, 20 \mathrm{~s}, 30 \mathrm{~s}, 40 \mathrm{~s}, 50 \mathrm{~s}$ and $60 \mathrm{~s}$

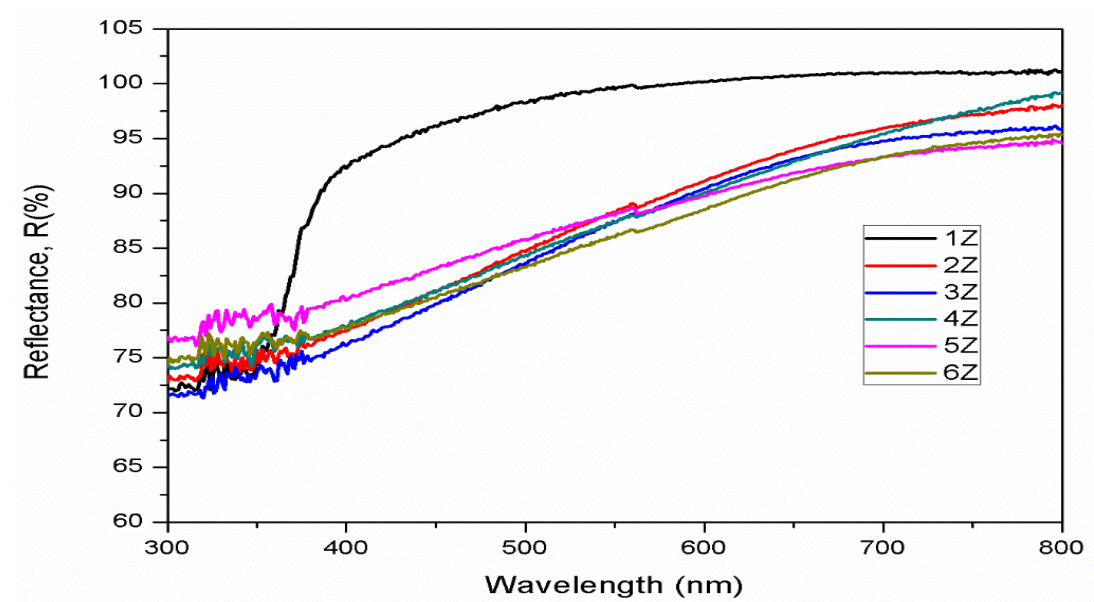

Figure 4. Optical reflectance spectra of AZO thin films prepared at $45 \mathrm{~cm}$ substrate to nozzle distance and six different spray time which are $10 \mathrm{~s}, 20 \mathrm{~s}, 30 \mathrm{~s}, 40 \mathrm{~s}, 50 \mathrm{~s}$ and $60 \mathrm{~s}$ 
The optical band gap, Eg of AZO thin film can be estimated by the Tauc plot of the Kubelka-Munk function. According to the Kubelka-Munk function relation:

$$
F(R)=\frac{K}{S}=\frac{(1-R)^{\wedge} 2}{2 R}
$$

where $\mathrm{K}$ is the molar absorption coefficient and $\mathrm{S}$ is the scattering factor of the diffused reflectance of the film. The Kubelka-Munk function $\mathrm{F}(\mathrm{R})$ is directly proportional to the absorption factor, and inversely proportional to the scattering factor [29-31].

The direct band gap energy of deposited AZO thin films were obtained from the intercept of the energy axis, $y$-axis of the tangent to the curve of $(F(R) h v) 2(e V c m-1) 2$ vs (hv) curve shown in Figure 5(a), 5 (b) and 5(c) of sample $3 \mathrm{X}, 4 \mathrm{Y}$ and $1 \mathrm{Z}$ respectively. The optical band gap of the samples is found to be 3.13 $\mathrm{eV}, 3.06 \mathrm{eV}$ and $3.14 \mathrm{eV}$. The movement of the band gap owing to the increase of Fermi level in the conductive band of following semiconductor. From the result obtained, sample 4Y was found to be having the smallest value band gap which were $3.16 \mathrm{eV}$ than other samples. This can be related to the physical structure of the thin film where sample $4 \mathrm{Y}$ also have the greatest crystallinity compared to other samples referring to XRD result obtained. The physical structure of the film give impact to the conductivity of the thin film where high crystallinity thin film quality will give smaller band gap value thus giving a very conductive thin film. Therefore, it can be concluded that the optical band gap increases with increasing nozzle-substrate distance less than $40 \mathrm{~cm}$ then decreases after the distance of $40 \mathrm{~cm}$ as seen in Figures 5(a), $5(b)$ and 5(c). These decreases of optical band gap values due to the increase in optical disorder.
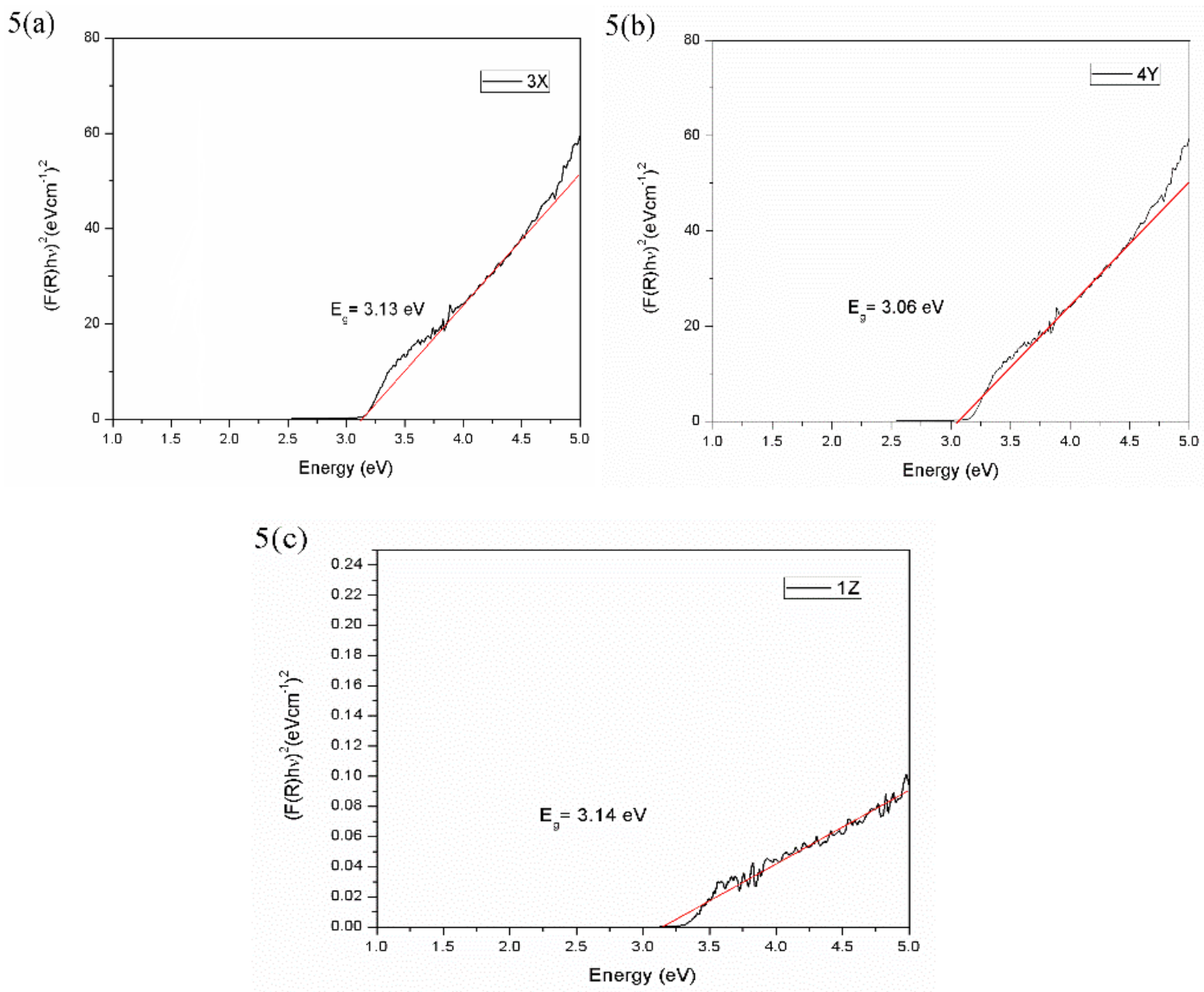

Figure 5. (a), (b) and (c): Plot of $(\mathrm{F}(\mathrm{R}) \mathrm{h} v) 2(\mathrm{eVcm}-1) 2$ vs (hv of sample $3 \mathrm{X}, 4 \mathrm{Y}$ and $1 \mathrm{Z}$ of AZO thin films 


\section{CONCLUSION}

Aluminium zinc oxide (AZO) thin films by spray pyrolysis method were successfully deposited onto Teflon substrate. All AZO thin films were characterized physically and optically in order to study its behaviour. The effect of nozzle-substrate distance and spray time on physical and optical properties of the Teflon films was investigated. According to the result obtain from the measurement process, the crystallinity of all Teflon thin films was improved with nozzle to substrate distance $(35 \mathrm{~cm}$ to $40 \mathrm{~cm})$ and spray time (30s to 40s). The optical characterization on a range of 300 to $800 \mathrm{~nm}$ showed that Teflon films have a reflectance of $80 \%$ where the optical band gap values for the variant spray time and nozzle to substrate distance were about 3.06 to $3.24 \mathrm{eV}$. For the future study, the structural and electrical properties will be explored for better understanding of the behaviour displayed by AZO thin film deposited onto Teflon substrate that can be applied in future device application.

\section{ACKNOWLEDGEMENTS}

The author would like to thank all members of Nano Electronic Centre (NET) and Universiti Teknologi MARA (UiTM) Shah Alam, UiTM Cawangan Pasir Gudang and Uitm Cawangan Pulau Pinang for all the research facilities.

\section{REFERENCES}

[1] A. S. Ismail et al., "Intrinsic $\mathrm{ZnO} / \mathrm{Al}$-doped $\mathrm{ZnO}$ homojunction: Structural and optical properties," Indones. J. Electr. Eng. Comput. Sci., vol. 12, no. 1, pp. 393-398, 2018.

[2] S. S. Shariffudin, P. S. M. Saad, H. Hashim, and M. H. Mamat, "Effect of deposition temperature on self-catalyzed $\mathrm{ZnO}$ nanorods via chemical vapour deposition method," Indones. J. Electr. Eng. Comput. Sci., vol. 11, no. 1, pp. 209-214, 2018.

[3] C. Y. Chi, H. I. Chen, W. C. Chen, C. H. Chang, and W. C. Liu, "Formaldehyde sensing characteristics of an aluminum-doped zinc oxide (AZO) thin-film-based sensor," Sensors Actuators, B Chem., vol. 255, pp. 3017-3024, Feb. 2018.

[4] D. Dastan, N. Chaure, and M. Kartha, "Surfactants assisted solvothermal derived titania nanoparticles: synthesis and simulation,” J. Mater. Sci. Mater. Electron., vol. 28, no. 11, pp. 7784-7796, Jun. 2017.

[5] L. Zhang, K. Jin, S. Li, L. Wang, Y. Zhang, and X. Li, "Synthesis of Flower-Like ZnO Films and Their Photovoltaic Properties for Dye-Sensitized Solar Cells,” J. Electron. Mater., vol. 44, no. 1, pp. 244-251, Jan. 2015.

[6] L. Dejam et al., "Correlation between surface topography, optical band gaps and crystalline properties of engineered AZO and CAZO thin films," Chem. Phys. Lett., vol. 719, pp. 78-90, Mar. 2019.

[7] G. K. Mani and J. B. B. Rayappan, "A highly selective room temperature ammonia sensor using spray deposited zinc oxide thin film,” Sensors Actuators B Chem., vol. 183, pp. 459-466, Jul. 2013.

[8] S. H. Ribut, C. A. Che Abdullah, and M. Z. Mohammad Yusoff, "Investigations of structural and optical properties of zinc oxide thin films growth on various substrates," Results Phys., vol. 13, p. 102146, Jun. 2019.

[9] M. Thirumoorthi and J. Thomas Joseph Prakash, "Doping effects on physical properties of (llll 010 ) oriented tin zinc oxide thin films prepared by nebulizer spray pyrolysis method," Mater. Sci. Eng. B, vol. 248, p. 114402, Sep. 2019.

[10] O. Karzazi et al., "Transparent conducting properties of $\mathrm{Mg}$ and $\mathrm{Al}$ co-doped $\mathrm{ZnO}$ thin films deposited by spray pyrolysis technique," Superlattices Microstruct., vol. 127, pp. 61-65, Mar. 2019.

[11] R. N. Ali, H. Naz, J. Li, X. Zhu, P. Liu, and B. Xiang, "Band gap engineering of transition metal (Ni/Co) codoped in zinc oxide (ZnO) nanoparticles," J. Alloys Compd., vol. 744, pp. 90-95, May 2018.

[12] M. Loeza-Poot, R. Mis-Fernández, I. Rimmaudo, E. Camacho-Espinosa, and J. L. Peña, "Novel sputtering method to obtain wide band gap and low resistivity in as-deposited magnesium doped zinc oxide films," Mater. Sci. Semicond. Process., vol. 104, p. 104646, Dec. 2019.

[13] M. K. Debanath and S. Karmakar, "Study of blueshift of optical band gap in zinc oxide (ZnO) nanoparticles prepared by low-temperature wet chemical method," Mater. Lett., vol. 111, pp. 116-119, Nov. 2013.

[14] A. M. Darwish et al., "Thermoelectric properties of Al-doped ZnO composite films with polymer nanoparticles prepared by pulsed laser deposition," Compos. Part B Eng., vol. 167, pp. 406-410, Jun. 2019.

[15] Y. Liu and S. Zhu, "Preparation and characterization of $\mathrm{Mg}, \mathrm{Al}$ and $\mathrm{Ga}$ co-doped $\mathrm{ZnO}$ transparent conductive films deposited by magnetron sputtering," Results Phys., vol. 14, p. 102514, Sep. 2019.

[16] J. S. Hong, H. Wagata, K. I. Katsumata, and N. Matsushita, "Low temperature Solution-Processed ZnO film on flexible substrate," Mater. Sci. Semicond. Process., vol. 47, pp. 20-24, Jun. 2016.

[17] A. A. M. Idris, R. Arsat, M. K. Ahmad, and F. Sidek, "Comparison of deposition methods of ZnO thin film on flexible substrate," Indones. J. Electr. Eng. Comput. Sci., vol. 5, no. 3, pp. 536-541, 2017.

[18] O. F. Farhat et al., "A study of the effects of aligned vertically growth time on $\mathrm{ZnO}$ nanorods deposited for the first time on Teflon substrate," Appl. Surf. Sci., vol. 426, pp. 906-912, Dec. 2017.

[19] O. F. Farhat, M. M. Halim, N. M. Ahmed, and M. A. Qaeed, "ZnO nanofiber (NFs) growth from ZnO nanowires (NWs) by controlling growth temperature on flexible Teflon substrate by CBD technique for UV photodetector," Superlattices Microstruct., vol. 100, pp. 1120-1127, Dec. 2016. 
[20] K. Necib, T. Touam, A. Chelouche, L. Ouarez, D. Djouadi, and B. Boudine, "Investigation of the effects of thickness on physical properties of AZO sol-gel films for photonic device applications," J. Alloys Compd., vol. 735, pp. 2236-2246, Feb. 2018.

[21] G. K. Mani and J. B. B. Rayappan, "A highly selective room temperature ammonia sensor using spray deposited zinc oxide thin film,” Sensors Actuators B Chem., vol. 183, pp. 459-466, Jul. 2013.

[22] J. Chao, Y. Chen, S. Xing, D. Zhang, and W. Shen, "Facile fabrication of $\mathrm{ZnO} / \mathrm{C}$ nanoporous fibers and $\mathrm{ZnO}$ hollow spheres for high performance gas sensor," Sensors Actuators B Chem., vol. 298, no. May, p. 126927, Nov. 2019.

[23] C. Y. Tsay and W. T. Hsu, "Comparative studies on ultraviolet-light-derived photoresponse properties of $\mathrm{ZnO}$, AZO, and GZO transparent semiconductor thin films," Materials (Basel)., vol. 10, no. 12, pp. 1-12, 2017.

[24] L. Dejam, S. Mohammad Elahi, H. H. Nazari, H. Elahi, S. Solaymani, and A. Ghaderi, "Structural and optical characterization of $\mathrm{ZnO}$ and $\mathrm{AZO}$ thin films: the influence of post-annealing," J. Mater. Sci. Mater. Electron., vol. 27, no. 1, pp. 685-696, Jan. 2016.

[25] N. Papež et al., "Degradation analysis of GaAs solar cells at thermal stress," Appl. Surf. Sci., vol. 461, pp. 212-220, Dec. 2018.

[26] A. Ashour, H. H. Afifi, and S. A. Mahmoud, "Effect of some spray pyrolysis parameters on electrical and optical properties of ZnS films," Thin Solid Films, vol. 248, no. 2, pp. 253-256, Aug. 1994.

[27] I. K. El Zawawi, M. A. Mahdy, and E. A. El-Sayad, "Influence of Film Thickness and Heat Treatment on the Physical Properties of Mn Doped Sb2Se3 Nanocrystalline Thin Films," J. Nanomater., vol. 2017, pp. 1-14, Apr. 2017.

[28] S. Hossain, G. D. A. Quaderi, K. M. A. Hussain, and T. Faruqe, "Synthesis and Characterization of Undoped and Aluminum Doped Zinc Oxide Thin Films using Thermal Evaporation Method,” vol. 27, no. 1, pp. 25-31, 2018.

[29] M. Patel, A. Chavda, I. Mukhopadhyay, J. Kim, and A. Ray, "Nanostructured SnS with inherent anisotropic optical properties for high photoactivity," Nanoscale, vol. 8, no. 4, pp. 2293-2303, 2016.

[30] P. D. Antunez, D. A. Torelli, F. Yang, F. A. Rabuffetti, N. S. Lewis, and R. L. Brutchey, "Low temperature solution-phase deposition of SnS thin films," Chem. Mater., vol. 26, no. 19, pp. 5444-5446, Oct. 2014.

[31] S. M. Herron, J. T. Tanskanen, K. E. Roelofs, and S. F. Bent, "Highly textured tin(II) sulfide thin films formed from sheetlike nanocrystal inks," Chem. Mater., vol. 26, no. 24, pp. 7106-7113, Dec. 2014.

\section{BIOGRAPHIES OF AUTHORS}

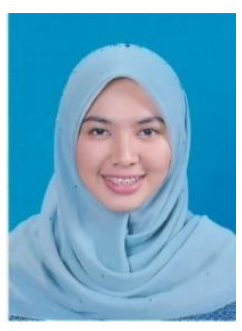

Sofea Nabila Binti Hazmin obtained Diploma in Science in 2015 and Bachelor of Industrial Physics (Hons) in 2018 from Universiti Teknologi MARA (UiTM), Malaysia. She is currently taking MSc of Electrical Engineering in UiTM. She is a member of UiTM Postgraduate Society.

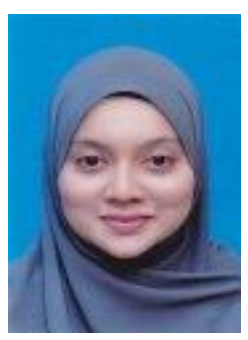

Dr. Nur Amalina Binti Muhamad is one of the members in the Board of Engineers Malaysia (BEM) and currently she is senior lecturer at Universiti Teknologi MARA (UiTM). She graduated Bacherlor and PhD in Electrical Engineering from UiTM. She also the head of Unit 'Pengajaran, Pembelajaran dan Latihan Staff', the academic advisor of UiTM Pasir Gudang Campus, committee of Malaysian Qualifications Agency (MQA) and committee of Academic Timetable of UiTM Campus.

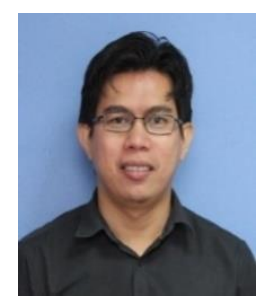

PM. Ir. Ts. Dr. Mohamad Hafiz Bin Mamat obtained his Bachelor of Electrical \& Electronic Engineering and Information Engineering from Nagoya University. Then, he further his studies at Universiti Teknologi MARA (UiTM), Malaysia taking MSc and Phd in Nanoelectronic. He is currently the head of NANO-ElecTronic Centre (NET) at Faculty of Electrical Engineering UiTM Shah Alam. 